\title{
The microsurgical anatomy of the glossopharyngeal nerve with respect to the jugular foramen lesions
}

\author{
Mehmet Faik ÖZveren, M.D., AND UĞUr Türe, M.D. \\ Department of Neurosurgery, Firat University School of Medicine, Elazig; and Ondokuz Mayis \\ University School of Medicine, Samsun, Turkey
}

\begin{abstract}
Removal of lesions involving the jugular foramen region requires detailed knowledge of the anatomy and anatomical landmarks of the related area, especially the lower cranial nerves. The glossopharyngeal nerve courses along the uppermost part of the jugular foramen and is well hidden in the deep layers of the neck, making this nerve is the most difficult one to identify during surgery. It may be involved in various pathological entities along its course. The glossopharyngeal nerve can also be compromised iatrogenically during the surgical treatment of such lesions. The authors define landmarks that can help identify this nerve during surgery and discuss the types of lesions that may involve each portion of the glossopharyngeal nerve.
\end{abstract}

\section{KEY WORDS • glossopharyngeal nerve • jugular foramen • lower cranial nerve • microsurgical anatomy}

\section{GLOSSOPHARYNGEAL NERVE ANATOMY}

The glossopharyngeal nerve can be divided into three portions: cisternal, jugular foramen, and extracranial.

\section{Cisternal Portion}

The rootlets of the glossopharyngeal nerve originate from the upper part of the postolivary sulcus of the medulla oblongata. These rootlets then usually form one root that courses forward and laterally on the anterior side of the flocculus and choroid plexus (Fig. 1). Its entrance porus is separated from the entrance of the vagus and accessory nerves by a dural crest in the jugular foramen (Fig. 2 ). The mean length of the cisternal portion of the glossopharyngeal nerve is $15 \mathrm{~mm} .{ }^{40}$ The VA is located below and behind the jugular foramen. The PICA runs very close to the four lower cranial nerves, loops around the hypoglossal nerve, and then courses along the fibers of the accessory nerve (Figs. 1 and 3 ).

The first landmarks of the glossopharyngeal nerve in the subarachnoid space are the flocculus and the choroid plexus of the lateral recess of the fourth ventricle..$^{40}$ The glossopharyngeal nerve may be compromised in this space by a vascular loop, a tortuous and ectatic basilar artery, an inflammatory process, a Chiari malformation, a neurenteric cyst, an exuberant choroid plexus, or a tumor. $7,8,16,21,22,25,29,31,33,38,48$ These pathological processes may cause glossopharyngeal neuralgia, ${ }^{7,25,31,38}$ paresis character-

Abbreviations used in this paper: $\mathrm{CCA}=$ common carotid artery; $\mathrm{ECA}=$ external CA; ICA = internal CA; IJV = internal jugular vein; $\mathrm{OA}=$ occipital artery; PICA = posterior inferior cerebellar artery; $\mathrm{SCM}=$ sternocleidomastoid; VA = vertebral artery. ized by dysphagia, loss of the gag reflex, or fullness in the pharynx..$^{8,27,30}$ They may also have a role in essential hypertension ${ }^{29,33}$ and syncope attacks. ${ }^{13,42}$ Exuberant choroid plexus tissue may become large enough to cause glossopharyngeal neuralgia. ${ }^{38}$ The vessel that most commonly causes glossopharyngeal neuralgia seems to be the PICA,${ }^{43}$ but the anterior inferior cerebellar artery can also compress the nerve. ${ }^{13,30,31,42}$ In some cases, vascular crosscompression by adhesions between the PICA or the VA and rootlets of the glossopharyngeal nerve was a factor in essential hypertension and syncope attacks either with or without glossopharyngeal neuralgia. $13,29,33,42$

Glossopharyngeal neuralgia is characterized by attacks of pain originating from the tonsil, tongue, or pharynx and radiating to the ear or the mandibular angle. ${ }^{7}$ The paroxysms are usually provoked by swallowing, especially of cold liquids, but coughing, sneezing, and touching the external meatus or ear lobe can also trigger pain. The pain may also begin in the ear and spread to the pharynx, which has led to a clinical distinction between the pharyngeal and tympanic types of glossopharyngeal neuralgia. Some investigators have described a cardiovascular type in which the neuralgia is accompanied by bradycardia and arterial hypotension that causes syncope and convulsions..$^{7,13}$ Glossopharyngeal neuralgia is classically divided into primary and secondary groups. No cause can be demonstrated in the primary type, but it is believed that trauma, elongation of the styloid process, inflammation, tumors, and vascular deformities may cause the secondary type.

The glossopharyngeal nerve generally is easily recognized within the lateral cerebellomedullary cistern in both normal anatomical conditions and cases of vascular compression. If the subarachnoid space is filled with tumor tis- 


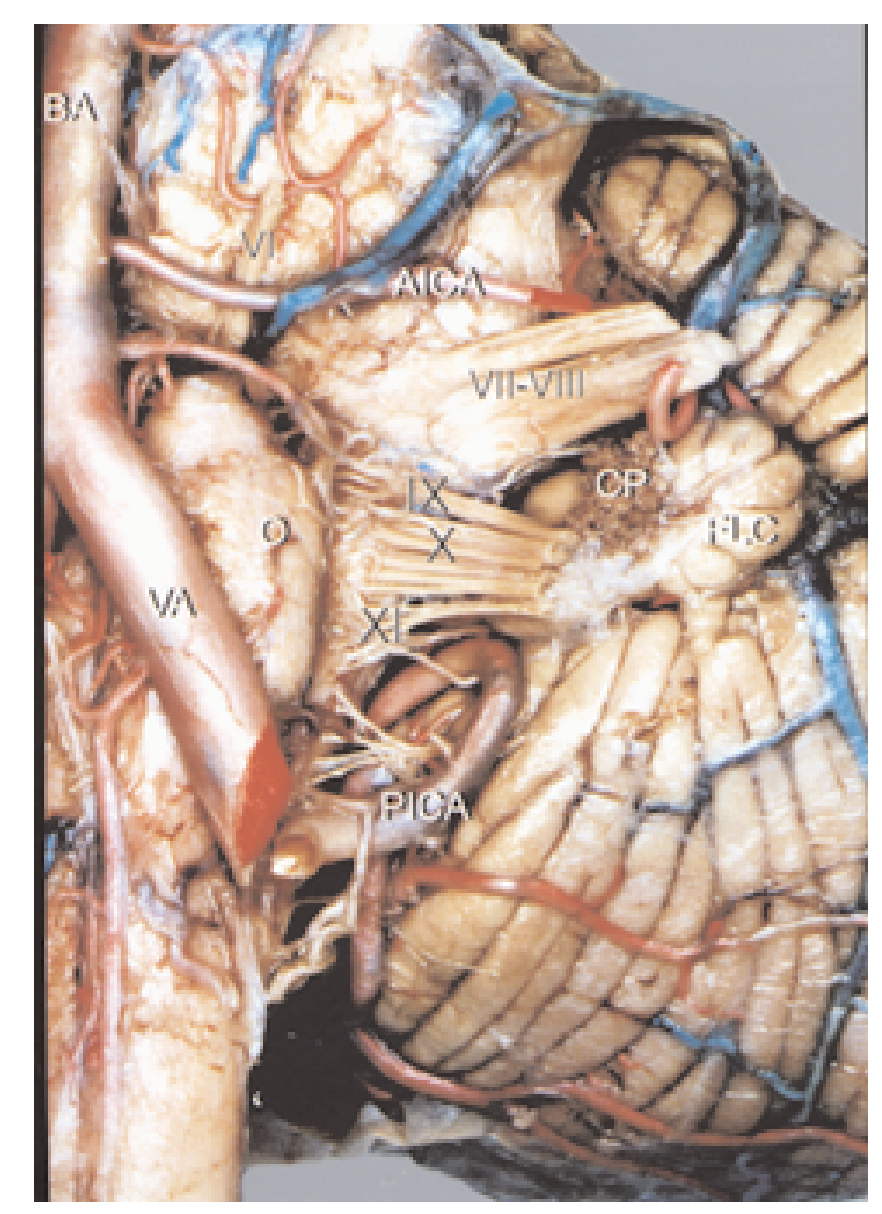

Fig. 1. Anterior view of the left cerebellopontine angle showing the origin of the glossopharyngeal nerve (IX) at the postolivary sulcus of the medulla oblongata. AICA = anteroinferior cerebellar artery; $\mathrm{BA}=$ basilar artery; $\mathrm{CP}=$ choroid plexus; $\mathrm{FLC}=$ flocculus; $\mathrm{O}=$ olive. Roman numerals denote cranial nerves. Reprinted with permission from Lippincott, Williams and Wilkins. Ozveren MF, et al: Anatomic landmarks of the glossopharyngeal nerve: a microsurgical anatomic study. Neurosurgery 52:1400-1410, 2003.

sue, however, the flocculus and choroid plexus may be distorted or may change their anatomical positions, and the glossopharyngeal nerve is not so easily recognized. Therefore, defining a constant landmark becomes critical. The glossopharyngeal nerve and the vagus and accessory nerve complex are consistently separated by a dural septum that forms two meatus on the intracranial side of the jugular foramen; these have been named the glossopharyngeal meatus and the vagal meatus. ${ }^{44}$ The dural septum that separates the glossopharyngeal nerve from the fascicles of the vagus and accessory nerves at the dural entrance of the glossopharyngeal nerve into the jugular foramen is a consistent structure. ${ }^{49}$ This is the second landmark of this nerve in the subarachnoid space. ${ }^{40}$

\section{Jugular Foramen Portion}

The cochlear aqueduct drains vertically into the entrance porus of the glossopharyngeal nerve (Figs. 2B and 3B). The nerve itself forms a genu inferiorly, approxi- mately $45^{\circ}$ from where it courses upward from its entrance porus. The nerve then travels through the jugular foramen in a channel leading from the pyramidal fossa below the opening of the cochlear aqueduct. Continuing on the medial side of the intrajugular ridge, this channel sometimes extends medially and surrounds the nerve to form a tunnel. The glossopharyngeal nerve courses through this tunnel on the medial aspect of the jugular bulb. The passage of the glossopharyngeal nerve in the jugular foramen is separated from the vagus and accessory nerves by a bone canal (Fig. 3A) or generally by a thick, fibrous band..$^{40}$ The glossopharyngeal nerve encounters the superior and inferior ganglia in its course inside the jugular foramen (Fig. 3B). The superior glossopharyngeal ganglion is located just below the opening of the cochlear aqueduct within the jugular foramen. The tympanic nerve (nerve of Jacobson) originates from the inferior ganglion and enters the inferior tympanic canaliculus, ascending in the canal on the medial wall of the middle ear, usually on the cochlear promontory (Figs. 3B and 4). ${ }^{17,40}$ The tympanic and superior and inferior caroticotympanic nerves form the tympanic plexus. ${ }^{57}$ This plexus supplies the mucous membrane of the tympanic cavity, the mastoid cells, and the auditory tube; parasympathetic fibers also pass through the tympanic plexus via the lesser petrosal nerve to the otic ganglion to supply the parotid gland. ${ }^{3,7,44,57} \mathrm{~A}$ branch from the tympanic plexus goes through an opening in front of the fenestra vestibuli and joins the greater petrosal nerve. ${ }^{57}$ The nerve of Arnold is the auricular branch of the superior ganglion of the vagus nerve (Fig. 4). It reaches the descending canal of the facial nerve through the mastoid canaliculus and supplies the back of the pinna and the external acoustic meatus. ${ }^{3}$ The nerve of Arnold also receives branches from the glossopharyngeal nerve, which exits the jugular foramen posteromedial to the styloid process and styloid muscles. The mean length of the jugular portion of the glossopharyngeal nerve is $10 \mathrm{~mm} .{ }^{40}$

The intrajugular processes of the temporal and occipital bones divide the anterior and posterior edges of the jugular foramen into sigmoid and petrosal parts. ${ }^{10,26,44}$ Occasionally, a deep groove is present along the medial extension of the intrajugular process of the temporal bone. This groove forms a canal that surrounds the glossopharyngeal nerve as it passes through the jugular foramen..$^{26,44}$ The genu is located at the external opening of the cochlear aqueduct. The bone canal of the glossopharyngeal nerve appears in fewer cases than the fibrous tissue separation., 9,26,44,54 Thus, the course of the glossopharyngeal nerve is separate from that of the vagus and accessory nerve complex inside the jugular foramen.

The glossopharyngeal, vagus, and accessory nerves are well protected in the bone structure of the jugular foramen. Nerve function lost by trauma indicates that the degree of trauma is very severe. ${ }^{37,56}$ If the lesion is a tumor, loss of nerve function indicates the highly invasive nature of the tumor. In addition to trauma, glomus jugulare tumors, chordomas, meningiomas, schwannomas, rhabdomyosarcomas, metastatic tumor invasion, infection, and cholesterol granulomas can also involve the glossopharyngeal nerve at the jugular foramen. ${ }^{1,2,10,24,27,37,48,56} \mathrm{Be}-$ cause the glossopharyngeal, vagus, and accessory nerves course together in the jugular foramen, lesions involving 


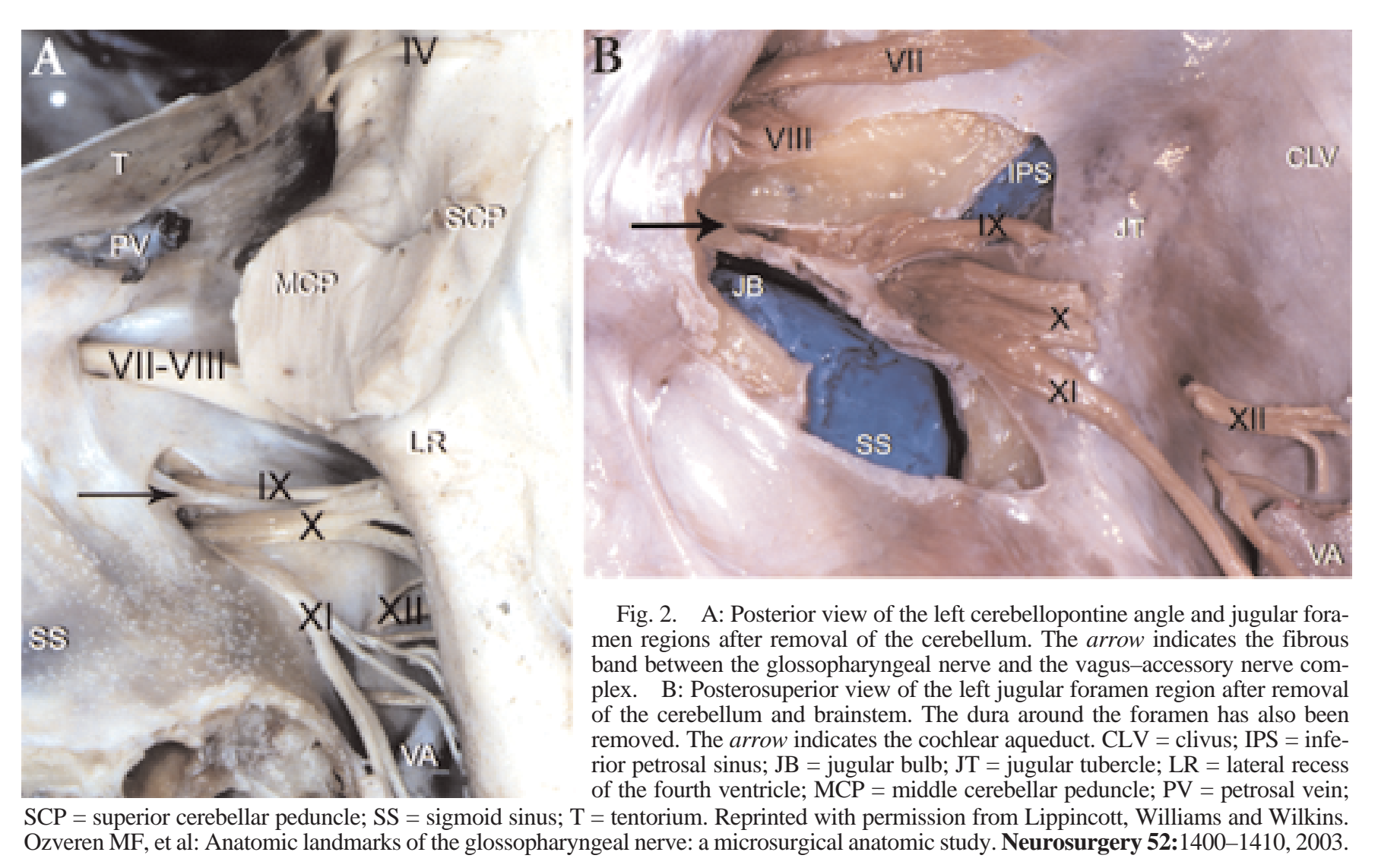

this structure generally affect the aforementioned nerves, as well as the hypoglossal nerve. The jugular foramen syndromes are characterized by involvement of these nerves. ${ }^{32,45}$

Glomus jugulare tumors are slow growing but are the most common ones found in the jugular foramen., ${ }^{1,10,23,45}$ These tumors originate from the "glomus bodies," which normally occur in the adventitia of the IJV and along nerves of the Jacobson and Arnold..$^{10,49}$ This site of origin of the glomus bodies means that a glomus jugulare tumor generally begins inside the jugular foramen. ${ }^{45}$ In advanced cases, these tumors grow in a variety of directions and may cause neurological symptoms, particularly involving the glossopharyngeal, vagus, and accessory nerves. ${ }^{10,34,49}$ More patients with these tumors exhibited deficits of the ninth through 12th cranial nerves postoperatively than before surgery. ${ }^{19,23}$ The postoperative functional result is directly related to the tumor's size and the preoperative status of the cranial nerves. ${ }^{23}$

Schwannomas arising from the glossopharyngeal nerve are relatively uncommon and are included under the heading of jugular foramen schwannomas. ${ }^{10,20,23,47,58}$ The symptoms at presentation depend on the origin of the nerve, but this may not be true in cases of jugular foramen tumors, because the compartment is so small that all cranial nerves may be affected at the same time. ${ }^{47}$ Because a schwannoma begins in the subarachnoid space, hearing loss accompanies the signs of lower cranial nerve palsy. Nevertheless, dysphagia or the loss of the gag reflex may be the only sign of a glossopharyngeal nerve neuroma. ${ }^{20}$ These Schwann cell-derived tumors usually originate intracra- nially and extend inferiorly into the jugular foramen..$^{45}$ Therefore, pressure erosion is common in patients with jugular foramen schwannomas, but in contrast to glomus jugulare tumors, bone invasion is rare. Because schwannomas are benign, the goal of therapy is total removal. ${ }^{20,47,58} \mathrm{~A}$ primary meningioma of the jugular fossa is one of the rarest types of meningiomas. ${ }^{2,23}$ In many respects, jugular foramen meningiomas mimic glomus jugulare tumors and lower cranial nerve neuromas. Clinically, however, their treatment may be even more fraught with difficulties because of their intimate relationship with the lower cranial nerves and the jugular bulb and vein, the involvement of the temporal bone, and their tendency to extend intra- or extracranially. ${ }^{2}$ The lack of a fibrous sheath leads to more extensive involvement of the lower cranial nerves. ${ }^{23}$ Therefore, sparing the lower cranial nerves is more difficult in patients with meningiomas than in those with glomus jugulare tumors or neuromas. . $2,23,47^{2}$

The superior ganglion of the glossopharyngeal nerve is small, has no branches, and is regarded as a detached part of the inferior ganglion. ${ }^{57}$ The glossopharyngeal nerve communicates with the sympathetic trunk and the vagus facial nerves. ${ }^{28,52,57}$ The superior and inferior ganglia of the vagus nerve supply the anastomoses between the lower cranial nerves. The superior vagus ganglion connects to the cranial root of the accessory nerve, the inferior glossopharyngeal ganglion, and the sympathetic trunk by a filament from the superior glossopharyngeal ganglion. ${ }^{57}$ The inferior ganglion of the vagus nerve connects to the hypoglossal nerve, the first and second cervical nerves, and the superior cervical sympathetic ganglion. ${ }^{57}$ From a surg- 


\section{F. Özveren and U. Türe}

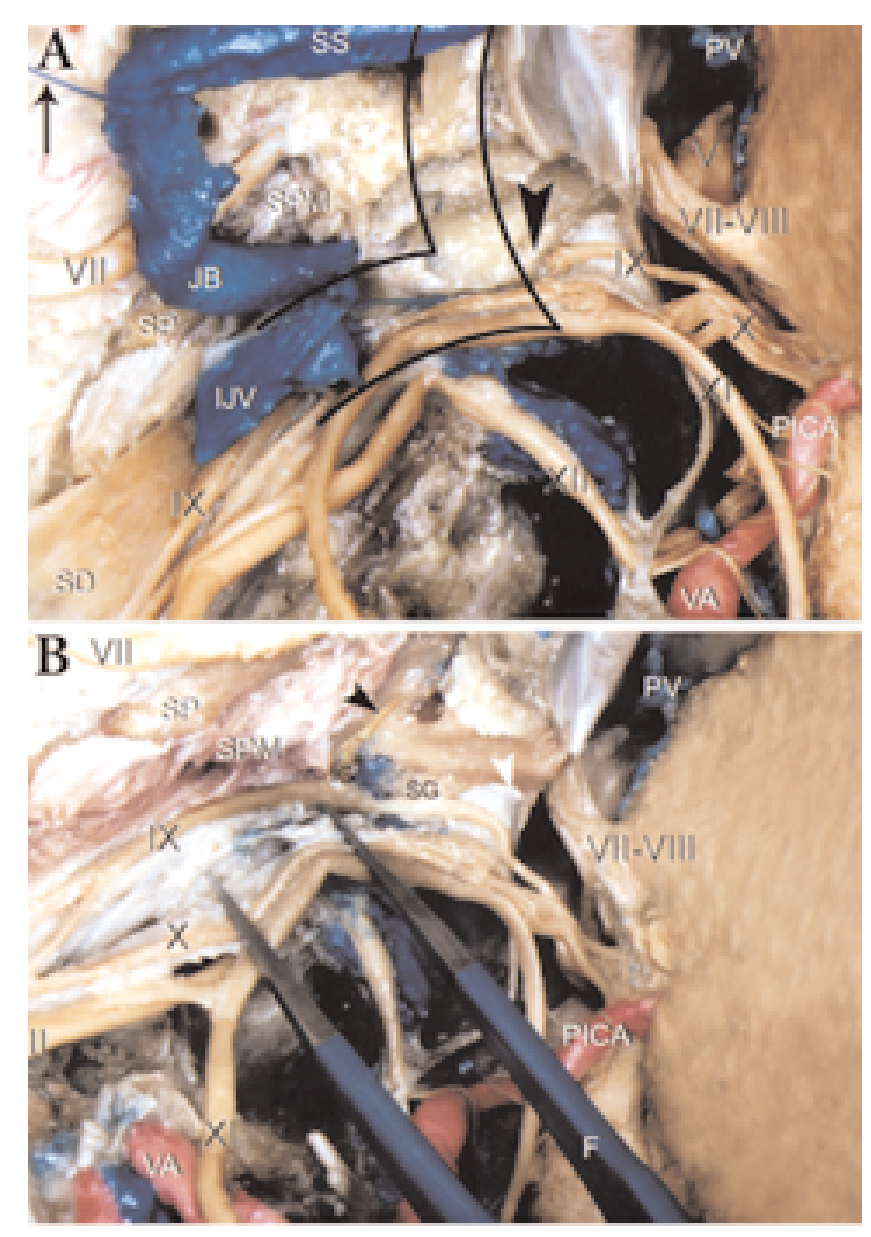

Fig. 3. A: Posterior view of the left jugular foramen region. The sigmoid sinus and jugular bulb have been retracted from their original positions (black lines) to show the lower cranial nerves. The glossopharyngeal nerve passes through a bone canal (arrowhead). The arrow indicates the thread retracting the sigmoid sinus. B: The jugular foramen has been opened, and the sigmoid sinus, jugular bulb, and IJV have been removed. The superior (SG) and inferior (IG) ganglia of the glossopharyngeal nerve are demonstrated. The black arrowhead indicates the tympanic (Jacobson) nerve, and the white arrowhead the opening of the cochlear aqueduct. $\mathrm{F}=$ forceps; $\mathrm{SD}=$ styloid diaphragm; $\mathrm{SP}=$ styloid process; SPM $=$ stylopharyngeal muscle. Reprinted with permission from Lippincott, Williams and Wilkins. Ozveren MF, et al: Anatomic landmarks of the glossopharyngeal nerve: a microsurgical anatomic study. Neurosurgery 52:1400-1410, 2003.

ical point of view, these anastomoses may explain a patient's ability to tolerate cranial nerve dysfunction, both acutely and in the long term, even when the glossopharyngeal nerve has been totally removed. ${ }^{23,41}$ Jackson, et al., ${ }^{23}$ noted that the sacrifice of one of the lower cranial nerves (ninth-12th) is very well tolerated. In contrast, acute aggregate nerve loss causes considerable short-term morbidity. Enteral feeding tubes may be needed for alimentation in the postoperative setting, but the nerves eventually compensate, and patients are able to eat within weeks.

There are three landmarks for the glossopharyngeal nerve at the jugular foramen: the cochlear aqueduct opening, the inferior tympanic canaliculus, and the mastoid canaliculus. ${ }^{40}$ The cochlear aqueduct serves as a landmark

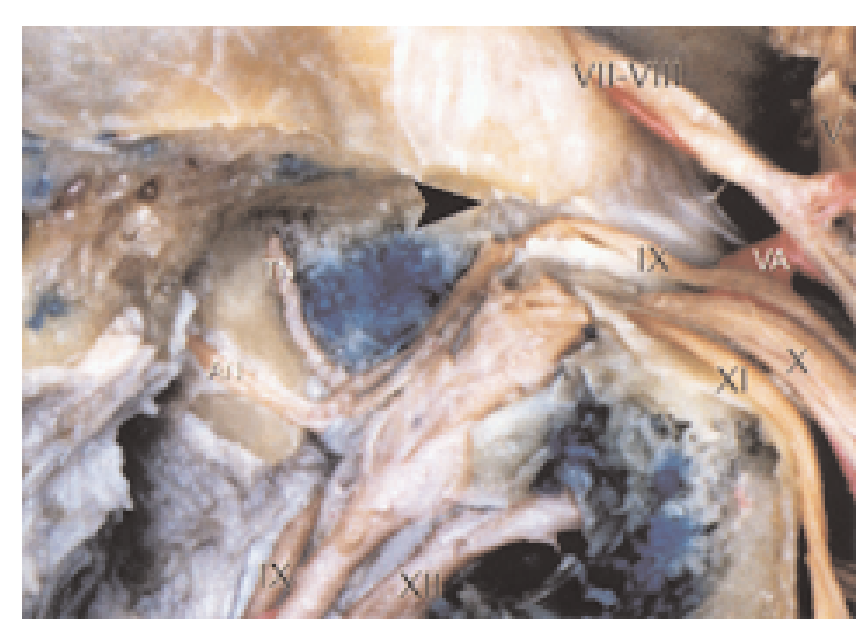

Fig. 4. The tympanic (Jacobson) nerve (TN) and Arnold nerve (AN) are shown within the left jugular foramen, posterior view. The arrowhead indicates the opening of the cochlear aqueduct. Reprinted with permission from Lippincott, Williams and Wilkins. Ozveren MF, et al: Anatomic landmarks of the glossopharyngeal nerve: a microsurgical anatomic study. Neurosurgery 52:1400-1410, 2003.

on the subarachnoid side of the glossopharyngeal nerve in the jugular foramen ${ }^{46}$ This aqueduct can be seen on thinslice, high-resolution computerized tomography scans. ${ }^{54}$ An intact cochlear aqueduct indicates that the glossopharyngeal nerve canal at the entrance has been spared. Therefore, an assessment of the condition of the cochlear aqueduct (intact or eroded) can be helpful before performing surgery in the jugular foramen region. Computerized tomography reliably demonstrates osseous erosion by a lesion.

Conversely, high-resolution surface-coil magnetic resonance images seem to be better for demonstrating the ninth through 11th cranial nerves within the jugular foramen and in extracranial tissues without a contrast agent. ${ }^{9}$ The inferior tympanic and the mastoid canaliculi are landmarks of the glossopharyngeal nerve near its extracranial portion within the jugular foramen. ${ }^{26,40,44,53,54}$ The inferior tympanic canaliculus is located medial to the styloid process and the stylomastoid foramen (Fig. 3B). Both the inferior tympanic and mastoid canaliculi are tiny canals; therefore, they are not as good landmarks as the cochlear aqueduct. To know their correct anatomical location requires that the surgeon pay more attention to the exit of the jugular foramen around the extracranial region. Furthermore, the surgeon must understand the origin of the pathological process. ${ }^{40}$ The nerve of Jacobson (tympanic nerve) has been involved in cases of schwannoma and glomus tympanicum tumors. ${ }^{3}$ The nerve of Arnold courses 1 to 2 $\mathrm{mm}$ lateral to the tympanic nerve. Thus, an injury to the nerve of Arnold might be more likely than an injury to the tympanic nerve during exposure of the jugular foramen. If the glossopharyngeal nerve courses through a bone canal, fibers must branch from this nerve and join with a branch of the vagus nerve to compose the Arnold nerve. Nevertheless, its exposure during surgery is very difficult.

\section{Extracranial Portion}

The transverse process of the atlas, or C-1, which is eas- 
ily palpated during the early phase of dissection, is a reliable guide when exposing the extracranial opening of the jugular foramen (Fig. 5). The accessory nerve crosses the IJV just after it exits the jugular foramen and passes through a space between the transverse process of the $\mathrm{C}-1$ and the styloid process to innervate the SCM muscle (Fig. $5)$. The cranial nerves of the jugular foramen are the two main nerve bundles in evidence after the extracranial exit point of the jugular foramen is exposed. The first bundle, at the upper portion and located deeper, belongs to the glossopharyngeal nerve. The second, which is more superficial than the first, belongs to the vagus and accessory nerve complex. The hypoglossal nerve is located lower and deeper than this second bundle (Fig. 6). All of these nerves are located medial to the IJV as they exit the jugular foramen..$^{40}$

The glossopharyngeal nerve is located posteromedial to the styloid process and styloid muscles and medial to the stylomastoid foramen as it exits the jugular foramen (Fig. 5 ). This nerve courses posteriorly to the stylopharyngeus muscle, innervates the muscle, and passes anteriorly to branch at the level of the middle constrictor muscle (Figs. 7 and 8). ${ }^{17}$ As it courses along the stylopharyngeus muscle, the glossopharyngeal nerve turns lateral and then anterior to the muscle. The glossopharyngeal nerve again turns to the medial side of the stylopharyngeus muscle and penetrates the pharynx wall just above the level of the middle constrictor muscle. It also branches to the tongue. The mean distance between its exit from the jugular foramen and its distribution in the pharynx mucosa is
$75 \mathrm{~mm} .{ }^{40}$ The vagus nerve courses downward between the ICA and the IJV. The connections between the vagus and glossopharyngeal nerves and between the vagus and hypoglossal nerves may be observed. A tiny branch from the glossopharyngeal nerve may communicate with another division from the vagus nerve and with a branch from sympathetic plexus to compose (the Hering carotid sinus) nerve, which innervates the baroreceptors in the wall of the carotid sinus and the chemoreceptors in the carotid body (Fig. 6) ${ }^{40,55,57}$ The accessory nerve may connect with the hypoglossal nerve (Fig. 7). ${ }^{40}$

The hypoglossal nerve passes through its own canal. The extracranial opening of the hypoglossal canal is located inferomedial to the extracranial opening of the jugular foramen (Figs. 2, 4, and 6). Although the hypoglossal nerve is located posterior to the ICA as it exits the hypoglossal canal, this nerve passes anterior to the ICA approximately $3 \mathrm{~cm}$ above the carotid bifurcation (Fig. 7). ${ }^{40}$ The descending branch of this nerve (upper root of ansa cervicalis) leaves the hypoglossal nerve where it turns round the $\mathrm{OA}$, and descends anterior to or in the sheath of the ICA and CCA. It contains no fibers from the hypoglossal nucleus, but only fibers from $\mathrm{C}-1$, which constitute the upper root of the ansa cervicalis. This nerve connection is a significant landmark to identify the hypoglossal nerve, and the upper root of the ansa cervicalis is called the descending ansa hypoglossi. ${ }^{6}$ The hypoglossal nerve is situated medial to the stylohyoid and the posterior belly of the digastric muscle before it angles above the hyoid bone (Fig. 8A)..$^{40}$

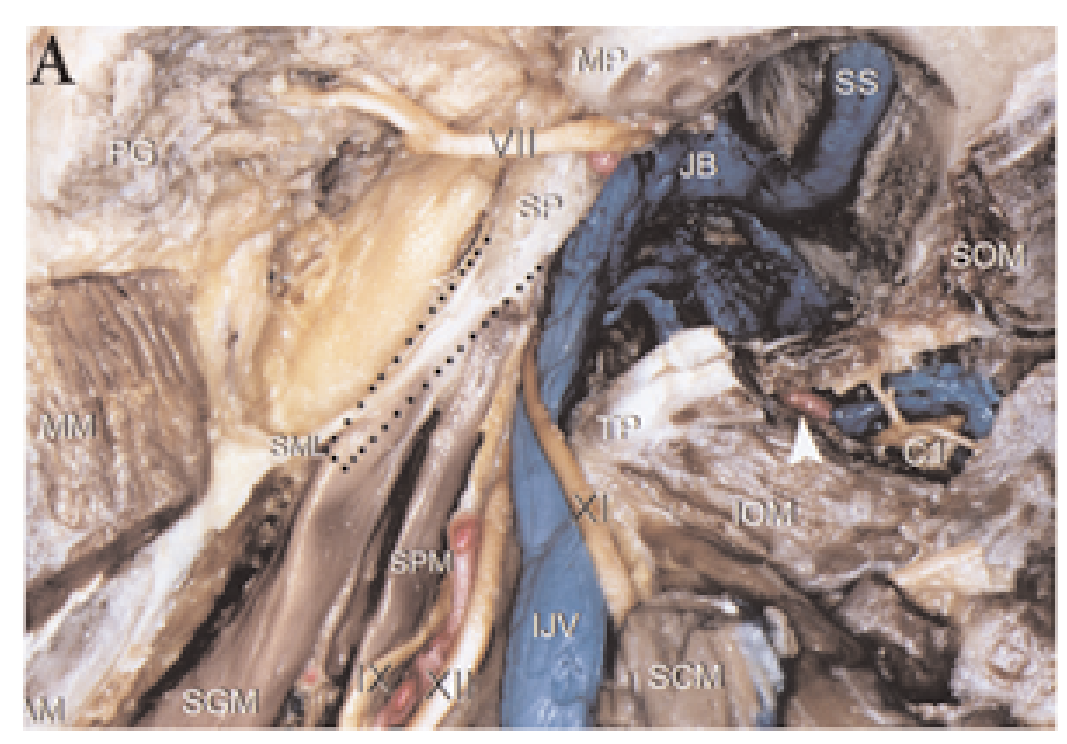

Fig. 5. A: Posterolateral view of the left jugular foramen region after the jugular foramen was opened. The ninth, 11th, and 12th cranial nerves and the IJV pass between the transverse process of the atlas (TP) and the styloid process (dotted line). The glossopharyngeal nerve courses behind the stylopharyngeus muscle. The arrowhead indicates the VA. B: Close-up view of the same specimen. The four lower cranial nerves pass through the bone prominence of the transverse process of the atlas and the styloid process. $\mathrm{AM}=$ angulus mandible; $\mathrm{C} 1=\mathrm{C}-1$ nerve root; $\mathrm{H}=$ hook $\mathrm{IOM}=$ inferior oblique muscle; $\mathrm{MM}=$ masseter muscle; $\mathrm{MP}=$ mastoid process; $\mathrm{PG}=$ parotid gland; $\mathrm{SCM}=\mathrm{SCM}$ muscle; $\mathrm{SGM}=$ styloglossus mus-

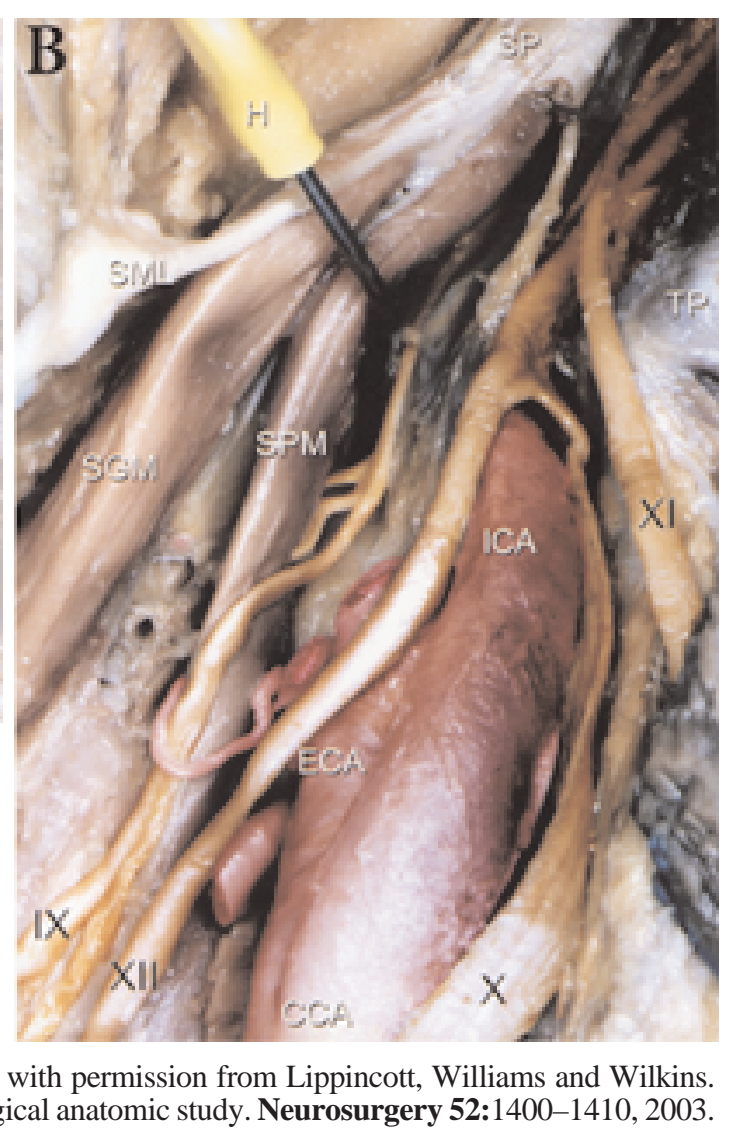

Ozveren MF, et al: Anatomic landmarks of the glossopharyngeal nerve: a microsurgical anatomic study. Neurosurgery 52:1400-1410, 2003. 


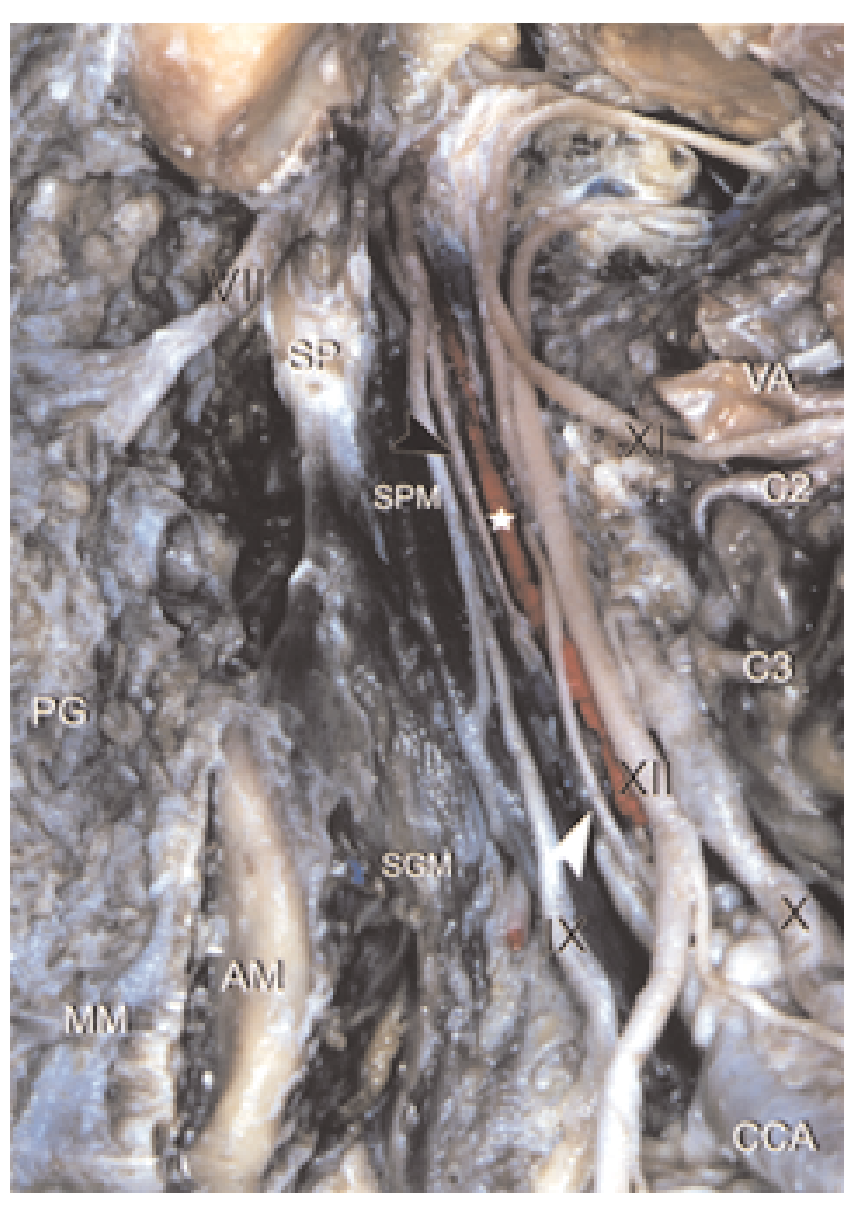

Fig. 6. Lateral view of the extracranial portions of the lower cranial nerves on the left side. The transverse process of the atlas has been removed, and the $\mathrm{V}_{3}$ segment of the VA has been exposed. A branch from the glossopharyngeal nerve (black arrowhead) joins a branch from the vagus nerve to form the Hering (carotid sinus) nerve (white arrowhead). The star indicates the ICA. C2 = C-2 nerve root; $\mathrm{C} 3=\mathrm{C}-3$ nerve root. Reprinted with permission from Lippincott, Williams and Wilkins. Ozveren MF, et al: Anatomic landmarks of the glossopharyngeal nerve: a microsurgical anatomic study. Neurosurgery 52:1400-1410, 2003.

The styloid diaphragm is a fibrous sheet originating at the styloid process. It contains the styloid group of muscles (the stylohyoid, styloglossus, and stylopharyngeus) and the posterior belly of the digastric muscle and joins the parotid fascia. The styloid diaphragm divides the infratemporal fossa into the prestyloid and retrostyloid spaces. ${ }^{5}$ The parotid gland and duct, the facial nerve, the ECA, and the OA are located in the prestyloid space (Fig. 7). The ICA, the OA, the IJV, and the beginning portions of the four lower cranial nerves are situated in the retrostyloid space (Fig. 7A). The lower limit of the styloid diaphragm seems to be approximately half way down the posterior belly of the digastric muscle. The hypoglossal nerve crosses under the styloid diaphragm before it angles to approach the base of the tongue (Figs. 8B and 9). ${ }^{40}$

The stylopharyngeus muscle attaches posterior to the styloid process, the stylohyoid muscle attaches anterolateral to the styloid process, and the styloglossus muscle attaches anteromedial to the styloid process (Figs. 9A and 10). Although the styloid diaphragm is composed of these

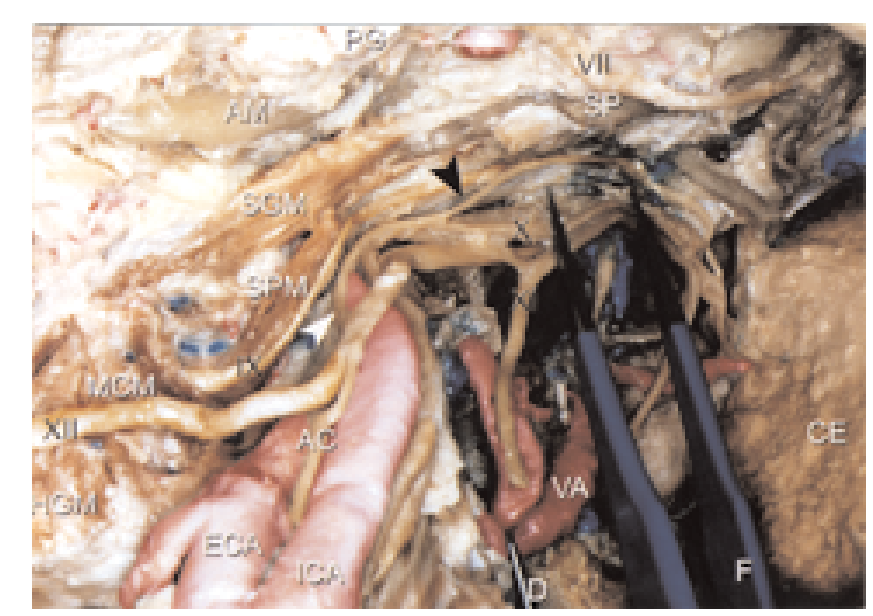

Fig. 7. On the left side of the specimen, a branch from the glossopharyngeal nerve (black arrowhead) joins a branch from the vagus nerve to form the Hering (carotid sinus) nerve (white arrowhead). Note also the connection of the accessory nerve (XI) with the hypoglossal nerve (XII). AC = ansa cervicalis of hypoglossal nerve; $\mathrm{CE}=$ cerebellum; $\mathrm{D}=$ dissector; $\mathrm{HGM}=$ hypoglossus muscle; $\mathrm{MCM}=$ middle constrictor muscle. Reprinted with permission from Lippincott, Williams and Wilkins. Ozveren MF, et al: Anatomic landmarks of the glossopharyngeal nerve: a microsurgical anatomic study. Neurosurgery 52:1400-1410, 2003.

three styloid muscles at the proximal portion, the three muscles distribute anteriorly (the styloglossus), laterally (the stylohyoid), and posteriorly (the stylopharyngeus) to form the base of a pyramid at the level of the middle constrictor muscle in the parapharyngeal space (Figs. 8 and 11). The styloid process forms the tip of this pyramid. The mean length of the styloid process is $20 \mathrm{~mm}{ }^{40}$

The styloglossus muscle forms the anteromedial wall, the stylopharyngeus muscle forms the posteromedial wall, and the stylohyoid muscle forms the lateral wall of this space. Because the styloid process and the styloid muscles form a pyramid, we call this space the styloid pyramid. ${ }^{40}$ Because the stylohyoid muscle attaches to the hyoid bone, it forms the lower limit of the lateral border of the styloid pyramid. The middle constrictor muscle separates the glossopharyngeal and the hypoglossal nerves at the base of this pyramid (Figs. 9 and 11). Although the styloid diaphragm is encapsulated by the styloid muscles on the upper side of the pyramid, the styloid diaphragm ends at the lower portions of these muscles (Fig. 8B). Thus a pyramid is formed, which contains the glossopharyngeal nerve, the hypoglossal nerve, the middle constrictor muscle, and the facial artery (Figs. 7-9). The glossopharyngeal nerve can be found at the base of the styloid pyramid, just superior and medial to the hypoglossal nerve, just above the point at which the hypoglossal nerve angles. Thus, the base of the styloid pyramid, which is formed by the hypoglossal nerve, the middle constrictor muscle, and the glossopharyngeal nerve from a lateral-tomedial direction, serves as a landmark of the glossopharyngeal nerve in the extracranial region. ${ }^{40}$ The middle constrictor muscle is located between the hypoglossal and the glossopharyngeal nerves at this level. The glossopharyngeal nerve is located medial to the stylohyoid ligament (Fig. 11). 


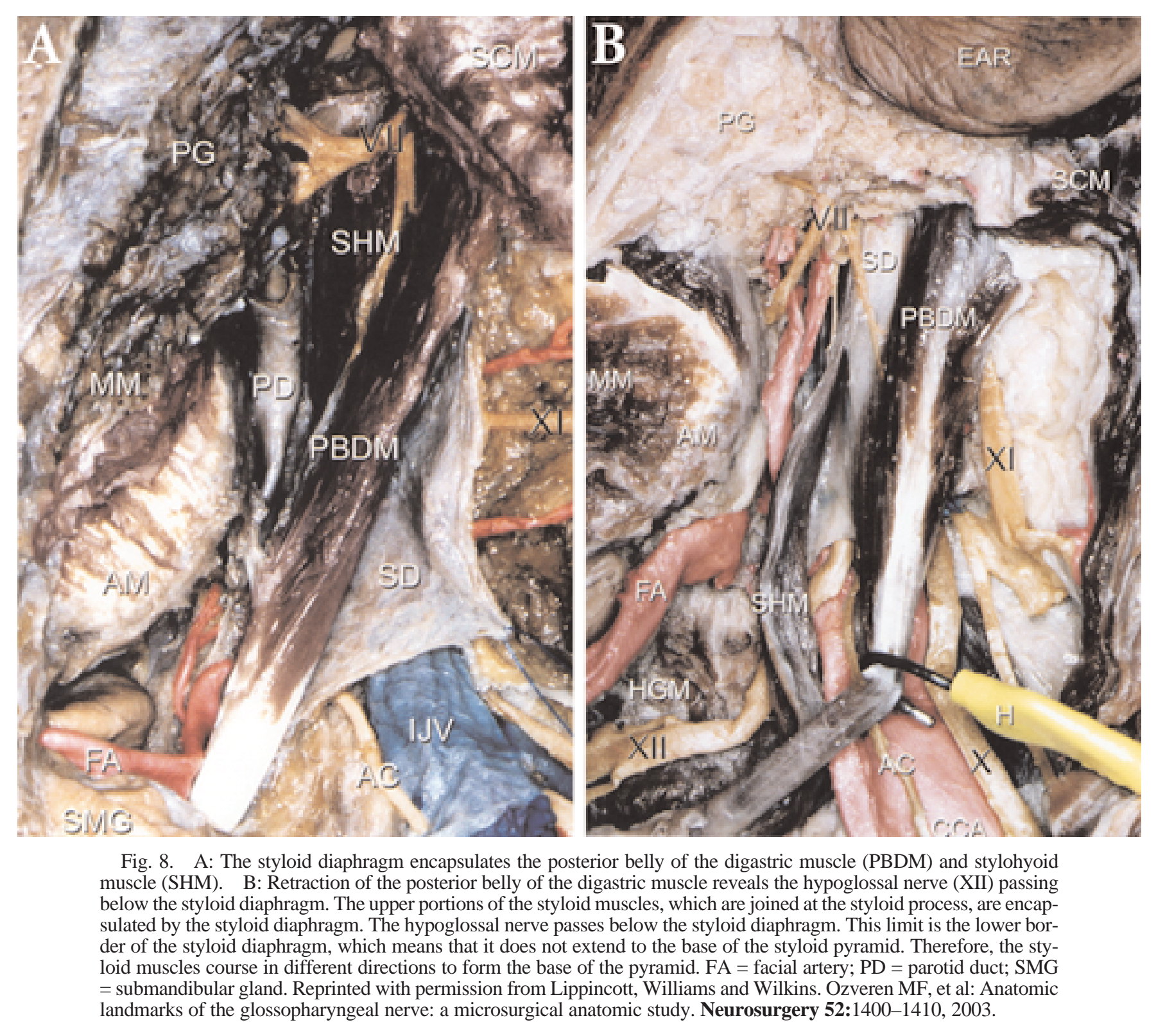

The complication rate for cranial nerve palsy after carotid endarterectomy ranges from 3 to $35 \%$. . $^{12,14,35,36}$ Nevertheless the glossopharyngeal nerve courses very deep in the infratemporal fossa and is not usually visualized during this procedure. Such an anatomical property decreases the chance of injury to the glossopharyngeal nerve during carotid surgery, which has been reported to be 0.3 to $0.4 \% .^{12,14}$ Although the rate of glossopharyngeal nerve palsy is low, such an injury may threaten a patient's nutritional status because it creates difficulty in swallowing. ${ }^{12,17}$ The hypoglossal and vagus nerves are most frequently injured after carotid endarterectomy because of their close relationship to the ICA. ${ }^{12,14,36}$ The exit point of the glossopharyngeal nerve from the jugular foramen is located just on the medial side of the styloid process and the stylomastoid foramen. Thus, the base of the styloid process is the first landmark for the extracranial portion of the glos- sopharyngeal nerve. An elongated styloid process can cause a pain syndrome in the throat known as the Eagle syndrome. ${ }^{11}$ This disorder is included as one of the causes of glossopharyngeal neuralgia.7.18,51 Because $4 \%$ of the surgical population had a styloid process of abnormal length $(30 \mathrm{~mm}),{ }^{7}$ elongation has not been accepted as a reasonable explanation for Eagle syndrome by some authors. ${ }^{18,51}$ Recently, this disorder was classified as an entrapment syndrome of the glossopharyngeal nerve..$^{51}$ The glossopharyngeal nerve passed medial to the stylohyoid ligament at the base of the styloid pyramid. We believe that this proximity may play a role in the appearance of glossopharyngeal neuralgia in patients without an elongated styloid process. Therefore, the stylohyoid ligament may play a role in Eagle's syndrome and that this syndrome may be classified as an entrapment syndrome of the glossopharyngeal nerve (Figs. 5 and 10). 


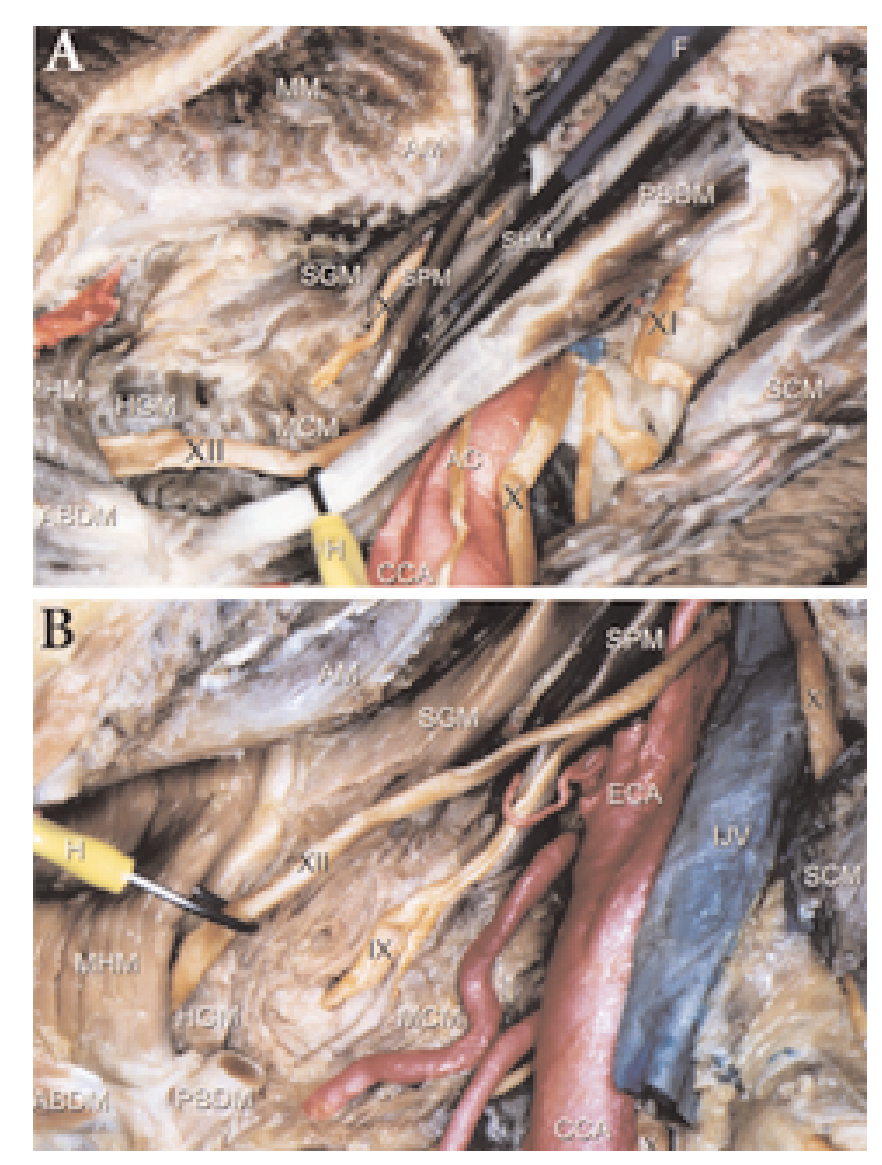

Fig. 9. Lateral view of the left side of the specimen. A: The glossopharyngeal nerve (IX) penetrates the wall of the pharynx through the medial side of the middle constrictor muscle. B: A close-up view of the penetration of the glossopharyngeal nerve into the pharynx wall. ABDM = anterior belly of the digastric muscle; MHM = mylohyoid muscle. Reprinted with permission from Lippincott, Williams and Wilkins. Ozveren MF, et al: Anatomic landmarks of the glossopharyngeal nerve: a microsurgical anatomic study. Neurosurgery 52:1400-1410, 2003.

George, et al., ${ }^{15}$ described the significance of removing the transverse process of the atlas to expose the lower cranial nerves, the ICA, and the IJV. Their juxtacondylar approach to the jugular foramen eliminated the need for drilling of the petrous bone and began a new era in surgery of the jugular foramen. The IJV rests against the transverse process of the atlas as it descends immediately below the jugular foramen. The glossopharyngeal nerve is located behind the posterior wall of the IJV (Fig. 5). Only the accessory nerve crosses over the IJV to innervate the SCM muscle at the level of the transverse process of the atlas. Other lower cranial nerves (ninth, 10th, and 12th) are situated on the medial side of the IJV at the level of the transverse process of the atlas (Fig. 5). There is a narrow space between the transverse process of the atlas and the styloid process at this level. The IJV is sometimes compressed by the transverse process at the site at which the vein descends across the process. This anatomical relationship was reported as a probable cause of cerebellar hemorrhage after supratentorial craniotomy. ${ }^{50}$ The transverse process of the atlas seems to be a significant anatomical structure

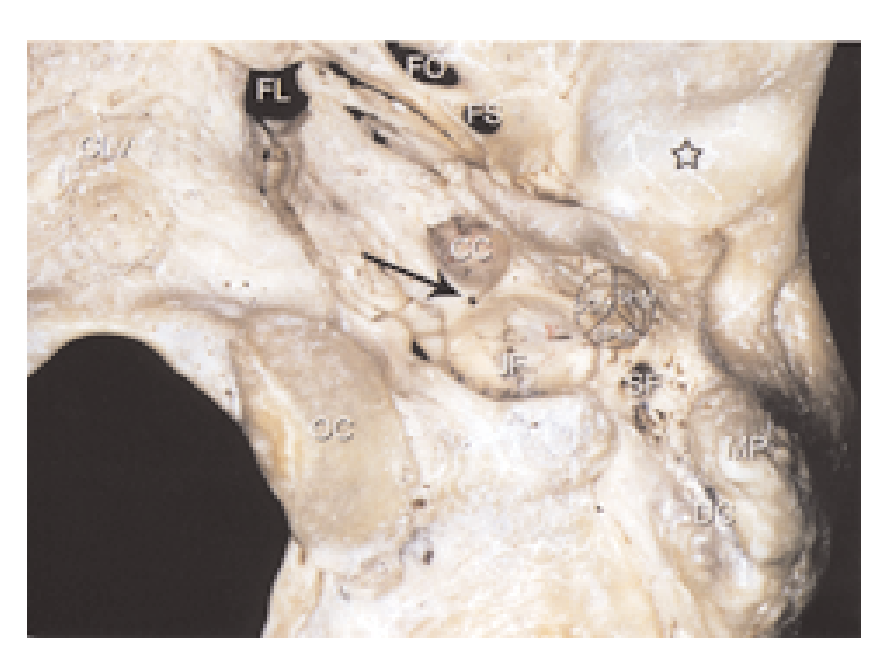

Fig. 10. Inferior view of the left side of the cranial base. Insertions of the styloid muscles at the styloid process are shown. The arrow indicates the inferior tympanic canaliculus, and the star indicates the fossa of the mandibular condyle. $\mathrm{CC}=$ carotid canal; $\mathrm{DG}=$ digastric groove; $\mathrm{FL}=$ foramen lacerum; $\mathrm{FO}=$ foramen ovale; FS = foramen spinosum; JF = jugular foramen; $\mathrm{OC}=$ occipital condyle; $\mathrm{SF}=$ stylomastoid foramen. Reprinted with permission from Lippincott, Williams and Wilkins. Ozveren MF, et al: Anatomic landmarks of the glossopharyngeal nerve: a microsurgical anatomic study. Neurosurgery 52:1400-1410, 2003.

that must be removed to expose the extracranial part of the glossopharyngeal nerve, other lower cranial nerves, and the IJV. Therefore, this process serves as the second landmark for the extracranial portion of the glossopharyngeal nerve. From the terminal part of the extracranial portion of the glossopharyngeal nerve, at the base of the styloid pyramid, the sensory branches distribute along the pharyngeal wall, and the lingual branch innervates the posterior part of the tongue. The lingual branch of the glossopharyngeal nerve adheres firmly to the tonsillary capsule. ${ }^{17,39}$ This relationship may disturb the patient's sense of taste after a tonsillectomy. Resecting the elongated styloid process through the pharynx may cause a similar complication. Although the glossopharyngeal nerve cannot be seen during the pharyngeal approach, it can be visualized during the submandibular infratemporal approach. The glossopharyngeal nerve can be seen at the base of the styloid pyramid, which is formed by the hypoglossal nerve, the middle constrictor muscle, and the glossopharyngeal nerve from the lateral to medial direction. This pyramid forms the third landmark for the glossopharyngeal nerve in the extracranial region.

\section{CONCLUSIONS}

The glossopharyngeal nerve is visualized through the choroid plexus of the lateral recess of the fourth ventricle and the dural entrance porus at the jugular foramen in the subarachnoid space. The opening of the cochlear aqueduct, the mastoid canaliculus, and the inferior tympanic canaliculus serve as landmarks of the glossopharyngeal nerve in the jugular foramen. The transverse process of the atlas, which obstructs the exposure of the lower four cranial nerves, serves as a significant landmark of the 


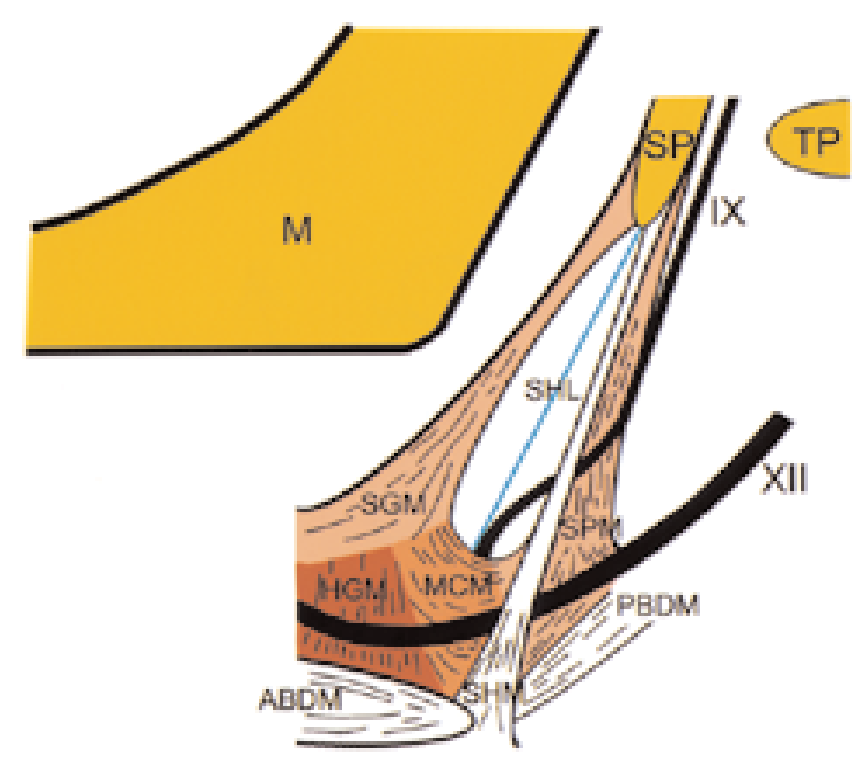

Fig. 11. Illustration of the left retromandibular region demonstrating the glossopharyngeal nerve (IX) and its relation to the muscle group. A pyramid is formed by the styloglossus, stylopharyngeus, and stylohyoid muscles. The styloid process forms the tip of the pyramid. The middle constrictor muscle separates the hypoglossal nerve (XII) and the glossopharyngeal nerve (IX). The glossopharyngeal nerve enters the medial side of the pyramid. $\mathrm{M}=$ mandible; SHL = stylohyoid ligament. Reprinted with permission from Lippincott, Williams and Wilkins. Ozveren MF, et al: Anatomic landmarks of the glossopharyngeal nerve: a microsurgical anatomic study. Neurosurgery 52:1400-1410, 2003.

glossopharyngeal nerve in the extracranial region. The base of the styloid process and the base of the styloid pyramid are other significant anatomical structures that can be used to locate the glossopharyngeal nerve in the extracranial region.

\section{References}

1. Al-Mefty O, Fox JL, Rifai A, et al: A combined infratemporal and posterior fossa approach for the removal of giant glomus tumors and chondrosarcomas. Surg Neurol 28:423-431, 1987

2. Arnautovic KI, Al-Mefty O: Primary meningiomas of the jugular fossa. J Neurosurg 97:12-20, 2002

3. Aydin K, Maya MM, Lo WW, et al: Jacobson's nerve schwannoma presenting as middle ear mass. AJNR 21:1331-1333, 2000

4. Ayeni SA, Ohata K, Tanaka K, et al: The microsurgical anatomy of the jugular foramen. J Neurosurg 83:903-909, 1995

5. Bejjani GK, Sullivan B, Salas-Lopez E, et al: Surgical anatomy of the infratemporal fossa: the styloid diaphragm revisited. Neurosurgery 43:842-853, 1998

6. Buchheit WA, Getch CC: Tumors of the cerebellopontine angle: clinical features and surgical management via retrosigmoid approach, in Wilkins RH, Rengachary SS (eds): Neurosurgery, ed 2. New York: McGraw-Hill, 1996, pp 1085-1094

7. Claes J: Nervus glossopharyngeus (N. IX). Acta Otorhinolaryngol Belg 40:207-214, 1986

8. Clairmont AA, Conley JJ: Malignant schwannoma of the parapharyngeal space. J Otolaryngol 6:28-30, 1977

9. Daniels DL, Schenck JF, Foster T, et al: Magnetic resonance imaging of the jugular foramen. AJNR 6:699-703, 1985

10. DiChiro G, Fisher RL, Nelson KB: The jugular foramen. J Neurosurg 21:447-460, 1964
11. Eagle WW: Elongated styloid processes. Report of two cases. Arch Otolaryngol 25:584-587, 1937

12. Evans WE, Mendelowitz DS, Liapis CD, et al: Motor speech deficit following carotid endarterectomy. Ann Surg 196: 461-464, 1982

13. Ferrante L, Artico M, Nardacci B, et al: Glossopharyngeal neuralgia with cardiac syncope. Neurosurgery 36:58-63, 1995

14. Forssell C, Kitzing P, Bergqvist D: Cranial nerve injuries after carotid artery surgery. A prospective study of 663 operations. Eur J Vasc Endovasc Surg 10:445-449, 1995

15. George B, Lot G, Tran Ba Huy P: The juxtacondylar approach to the jugular foramen (without petrous bone drilling). Surg Neurol 44:279-284, 1995

16. Goldenberg RA, Gardner G: Tumors of the jugular foramen: surgical preservation of neural function. Otolaryngol Head Neck Surg 104:129, 1991

17. Goodwin WJ Jr, Arnold D, Wachholz J: Surgical anatomy of the glossopharyngeal nerve. Laryngoscope 103:1302-1304, 1993

18. Gossman JR Jr, Tarsitano JJ: The styloid-stylohyoid syndrome. J Oral Surg 35:555-560, 1977

19. Green JD Jr, Brackmann DE, Nguyen CD, et al: Surgical management of previously untreated glomus jugulare tumors. Laryngoscope 104:917-924, 1994

20. Hakuba A, Hashi K, Fujitani K, et al: Jugular foramen neurinomas. Surg Neurol 11:83-94, 1979

21. Harris CP, Dias MS, Brockmeyer DL, et al: Neurenteric cysts of the posterior fossa: recognition, management, and embryogenesis. Neurosurgery 29:893-898, 1991

22. Hoffman RM, Stiller RA: Resolution of obstructive sleep apnea after microvascular brainstem decompression. Chest 107: 570-572, 1995

23. Jackson CG, Cueva RA, Thedinger BA, et al: Cranial nerve preservation in lesions of the jugular fossa. Otolaryngol Head Neck Surg 105:687-693, 1991

24. Joki-Erkilla VP, Hietaharju A, Numminen J, et al: Multiple cranial nerve palsies as a complication of infectious mononucleosis due to inflammatory lesion in jugular foramen. Ann Otol Rhinol Laryngol 109:340-342, 2000

25. Kanpolat Y, Unlu A, Savas A, et al: Chiari Type I malformation presenting as glossopharyngeal neuralgia: case report. Neurosurgery 48:226-228, 2001

26. Katsuta T, Rhoton AL Jr, Matsushima T: The jugular foramen: microsurgical anatomy and operative approaches. Neurosurgery 41:149-202, 1997

27. Kawahara N, Sasaki T, Nibu K, et al: Dumbbell type jugular foramen meningioma extending both into the posterior cranial fossa and into the parapharyngeal space: report of 2 cases with vascular reconstruction. Acta Neurochir 140:323-331, 1998

28. Kawai K, Kodama K, Okamoto K: Proximal communication between the glossopharyngeal and facial nerves. Acta Anat 134:151-155, 1989

29. Kleineberg B, Becker H, Gaab MR, et al: Essential hypertension associated with neurovascular compression: angiographic findings. Neurosurgery 30:834-841, 1992

30. Kondo A: Follow-up results of using microvascular decompression for treatment of glossopharyngeal neuralgia. J Neurosurg 88:221-225, 1998

31. Laha RK, Jannetta PJ: Glossopharyngeal neuralgia. J Neurosurg 47:316-320, 1977

32. Lang J: Clinical Anatomy of the Posterior Cranial Fossa and Its Foramina. New York: Thieme Medical Publishers, 1991, pp 92-96

33. Levy EI, Scarrow AM, Jannetta PJ: Microvascular decompression in the treatment of hypertension: review and update. Surg Neurol 55:2-11, 2001

34. Makek M, Franklin DJ, Zhao JC, et al: Neural infiltration of glomus temporale tumors. Am J Otol 11:1-5, 1990

35. Maniglia AJ, Han PD: Cranial nerve injuries following carotid 
endarterectomy: an analysis of 336 procedures. Head Neck 13: 121-124, 1991

36. Maroulis J, Karkanevatos A, Papakostas K, et al: Cranial nerve dysfunction following carotid endarterectomy. Int Angiol 19: 237-241, 2000

37. Miyazaki C, Katsume M, Yamazaki T, et al: Unusual occipital condyle fracture with multiple nerve palsies and Wallenberg syndrome. Clin Neurol Neurosurg 102:255-258, 2000

38. Occhiogrosso M, De Tommasi A, Vailati G: Glossopharyngeal neuralgia due to exuberant choroid plexus. Surg Neurol 13: 459-461, 1980

39. Ohtsuka K, Tomita H, Murakami G: [Anatomical study of the tonsillar bed: the topographical relationship between the palatine tonsil and the lingual branch of the glossopharyngeal nerve.] Nippon Jibiinkoka Gakkai Kaiho 97:1481-1493, 1994 (Jpn)

40. Ozveren MF, Ture U, Ozek MM, et al: Anatomic landmarks of the glossopharyngeal nerve: a microsurgical anatomic study. Neurosurgery 52:1400-1410, 2003

41. Patel SJ, Sekhar LN, Cass SP, et al: Combined approaches for resection of extensive glomus jugulare tumors. A review of 12 cases. J Neurosurg 80:1026-1038, 1994

42. Reddy K, Hobson DE, Gomori A, et al: Painless glossopharyngeal "neuralgia" with syncope: a case report and literature review. Neurosurgery 21:916-919, 1987

43. Resnick DK, Jannetta PJ, Bissonnette D, et al: Microvascular decompression for glossopharyngeal neuralgia. Neurosurgery 36:64-69, 1995

44. Rhoton AL Jr: Jugular foramen. Neurosurgery 47 (Suppl 3): S267-S285, 2000

45. Robbins KT, Fenton RS: Jugular foramen syndrome. J Otolaryngol 9:505-516, 1980

46. Rutka J, Nedzelski J: Translabyrinthine identification of the cochlear aqueduct: a helpful landmark during inferomedial temporal bone dissection. J Otolaryngol 20:184-187, 1991

47. Samii B, Babu RP, Tatagiba M, et al: Surgical treatment of jugular foramen schwannomas. J Neurosurg 82:924-932, 1995

48. Sekhar LN, Schramm VL Jr, Jones NF: Subtemporal-preauric- ular infratemporal fossa approach to large lateral and posterior cranial base neoplasms. J Neurosurg 67:488-499, 1987

49. Sen C, Hague K, Kacchara R, et al: Jugular foramen: microscopic anatomic features and implications for neural preservation with reference to glomus tumors involving the temporal bone. Neurosurgery 48:838-848, 2001

50. Seoane E, Rhoton AL Jr: Compression of the internal jugular vein by the transverse process of the atlas as the cause of cerebellar hemorrhage after supratentorial craniotomy. Surg Neurol 51:500-505, 1999

51. Slavin KV: Eagle syndrome: entrapment of the glossopharyngeal nerve? Case report and review of the literature. J Neurosurg 97:216-218, 2002

52. Tanaka S, Mizukami S: Vagal communicating branches between the facial and glossopharyngeal nerves, with references to their occurrence from the embryological point of view. Acta Anat 142:25-32, 1991

53. Tekdemir I, Aslan A, Tuccar E, et al: An anatomical study of the tympanic branch of the glossopharyngeal nerve (nerve of Jacobson). Anat Anz 180:349-352, 1998

54. Tekdemir I, Tuccar E, Aslan A, et al: The jugular foramen: a comparative radioanatomic study. Surg Neurol 50:557-562, 1998

55. Tubbs RS, Patwardhan RV, Oakes WJ: Ninth cranial nerve stimulation for epilepsy control. Part 2: surgical feasibility in humans. Pediatr Neurosurg 36:244-247, 2002

56. Waga S, Kojima T: Glossopharyngeal neuralgia of traumatic origin. Surg Neurol 17:77-79, 1982

57. Williams PL, Warwick R: Gray's Anatomy, ed 36. New York: Churchill Livingstone, 1980, pp 1075, 1076, 1083, 1200, 1462

58. Yaşargil MG: Microneurosurgery: In 4 Volumes. Stuttgart: Georg Thieme, 1996, Vol IVB, pp 124-133

Manuscript received June 21, 2004.

Accepted in final form July 7, 2004.

Address reprint requests to: Uğur Türe, M.D., Department of Neurosurgery, Ondokuz Mayis University School of Medicine, $\mathrm{Ku}-$ rupelit, Samsun, Turkey. email: ugurture@tnn.net. 